\title{
Dignidade e educação infantil: visão de pais e educadores
}

\author{
Mara Aparecida Lissarassa Weber \\ Raquel Souza Lobo Guzzo \\ Pontifícia Universidade Católica de Campinas - Campinas, SP, Brasil
}

\section{Resumo}

O Estatuto da Criança e do Adolescente (ECA) fundamenta-se na Doutrina da Proteção Integral: liberdade, dignidade e respeito à criança. $\mathrm{Na}$ desigualdade social, é difícil a efetivação de direitos universais e sua aplicação. Este artigo é parte de um estudo sobre a compreensão que pais e educadores têm a respeito da garantia e da violação dos direitos de proteção à criança, com ênfase no direito à DIGNIDADE. A pesquisa foi realizada em uma escola pública de educação infantil, com encontros de discussão envolvendo pais e educadores. Foram utilizados, como fonte de dados, um roteiro para caracterizar os participantes e protocolos para o conceito da dignidade, da garantia e da violação deste direito em casa, na escola e na comunidade. Os resultados apontaram que a garantia à dignidade em casa está associada às condições materiais que pais têm para suprir as necessidades dos filhos e, caso contrário, se houver dificuldades financeiras, ela estará sendo violada. A falta de qualidade do ensino e o acesso desigual à educação foram também considerados fatores que violam a dignidade infantil na escola, enquanto que a carência de serviços públicos disponíveis e o desinteresse do Estado marcam a violação da dignidade na comunidade.

Palavras-chave: Políticas brasileiras para crianças e adolescentes, Dignidade, Psicólogo escolar.

\section{Dignity and the pre-school education: vision of parents and educators}

\begin{abstract}
The Statute of Children and Adolescents - ECA is based in a Doctrine of Integral Protection - liberty, dignity and respect to children. In the social inequalities, the realization of the universal rights and its application is difficult. This article is part of a study about the comprehension that parents and educators have about the guarantee and violation of the children's protection rights, with an emphasis in the DIGNITY right. The research was accomplished in a public pre-school, with discussion meetings involving parents and educators. It was used as data base a screenplay to characterize the participants and the protocols to the dignity concept and the guarantee of the violation of this right at home, at school, and in the community. The results showed the guarantee to dignity at home is associated to the material conditions that the parents have to supply the necessity of the children and, otherwise, if there is financial difficulty, the necessity will be violated. The lack of quality and the unequal access to education were also considered as factors that violate the child dignity at school, while the lack of available public services and the State disinterest mark the dignity infringement in the community.
\end{abstract}

Keywords: Brazilian politics to children and adolescents, Dignity, School psychologist.

Endereço para correspondência: Mara A. Lissarassa Weber. Av. Julio de Castilhos, 73. Bairro Centro, Santiado/RS, Brasil. CEP: 97700-000. E-mail: maraweber09@yahoo.com.br. Telefone: +55 5532512231.

Apoio financeiro: CAPES.

Sobre as autoras:

Mara A. Lissarassa Weber - doutora em Psicologia pelo Programa de Pós-Graduação em Psicologia da PUCCampinas.

Raquel Souza Lobo Guzzo - professora titular de Psicologia da PUC-Campinas e orientadora da tese de doutorado.

Artigo aceito durante a gestão do editor Gerson Tomanari. 


\section{Dignidad y educación preescolar: visión para padres y educadores}

\section{Resumen}

El Estatuto del Niños y del Adolescente (ECA) se basa en la doctrina de Protección Integral de libertad, dignidad y respeto al niño. En la desigualdad social es difícil la efectuación de los derechos universales y su aplicación. Este artículo forma parte de un estudio sobre la comprensión de que los padres y educadores tienen a respeto de la garantía y la violación de los derechos de protección de la infancia, con énfasis en el derecho a la DIGNIDAD. La encuesta se realizó en una escuela pública de educación infantil, con reuniones de discusión con la participación de padres y educadores. Se utilizó como fuente de datos una hoja de ruta para caracterizar los participantes y protocolos para el concepto de la dignidad y seguridad y la violación de este derecho en su casa, en la escuela y en la comunidad. Los resultados indicaron que la garantía a la dignidad en el hogar está asociada con las condiciones materiales que tienen los padres para satisfacer las necesidades de los niños y, en caso contrario, si hay dificultades financieras, ella está siendo violada. La falta de una educación de calidad y el acceso desigual a la educación también fueron considerados como factores que atentan contra la dignidad de los niños en la escuela, mientras que la falta de servicios públicos disponibles y el desinterés del Estado marcan la violación de la dignidad en la comunidad.

Palabras clave: Las políticas brasileñas para los niños y adolescentes, Dignidad, Psicólogo de la escuela.

\section{Introdução}

No modelo de sociedade em que vivemos, a família tem a responsabilidade pelos cuidados com suas crianças e por seu desenvolvimento. Essa tarefa começa a ser compartilhada com a escola, a partir do momento em que a criança passa a frequentá-la. A família e a escola se submetem às diferentes regras e normas presentes na vida em sociedade, no entanto, o compromisso com o desenvolvimento das crianças torna-se uma prioridade para diferentes grupos sociais.

A presente pesquisa insere-se em um contexto de contradições, onde, de um lado, aparecem leis universais a serem aplicadas a toda a população e, de outro lado, há diferentes segmentos sociais, os quais se desenvolvem sob diversas condições econômicas de vida. No ano de 1990, foi promulgado o Estatuto da Criança e do Adolescente (ECA), o qual trouxe, em seu bojo, a doutrina da proteção integral às crianças, fundada na trilogia da liberdade, da dignidade e do respeito. Com uma formulação universal, o ECA, no entanto, configura-se em um instrumento para a efetivação da política de proteção à criança, sendo pouco refletido na prática cotidiana de educadores, pais e psicólogos neste contexto.

Autores como Martínez (2007), Souza (2007), Vectore e Maimoni (2007), Guzzo (2005) evidenciam que a formação e a atuação do Psicólogo Escolar caminham cada vez mais direcionadas para o conhecimento e o debate de temas relacionados às políticas públicas. No entanto, ainda existe a necessidade de discussões sobre a interação constante do psicólogo, dos educadores, dos pais e das próprias crianças em instituições educativas, pensando e propondo ações do cotidiano relacionadas a temas tais como políticas de prevenção e proteção infanto-juvenis, tendo como pano de fundo o ECA.

\section{O problema}

A nossa inserção em uma escola de educação infantil aconteceu por meio do projeto "Do Risco à Proteção: uma intervenção preventiva na comunidade", o qual englobava os projetos Voo da Águia, Vivendo Valores, Capacitação Docente e Capacitação Técnica. O projeto Voo da Águia era específico do espaço escolar, sendo uma proposta longitudinal e preventiva de intervenção de psicólogos nessas instituições.

Diante da realidade da escola, questionávamos a relação entre educadores $\mathrm{e}$ crianças que viviam realidades tão distintas, uma vez que, muitas mães, moradoras das favelas, trabalhavam nas casas das educadoras, moradoras dos condomínios próximos à escola.

A evidente desigualdade entre a vida das educadoras e das crianças teria impacto nas 
relações na escola? De que maneira a compreensão que pais e educadores tinham sobre o valor da dignidade na vida interferia nas relações com as crianças? Será que o direito à dignidade era realmente assegurado, tanto na escola, quanto na família? De que maneira o psicólogo escolar poderia contribuir para as relações entre educadores e famílias com realidades de vida tão diferentes? Muitas questões foram formuladas em função da inserção profissional neste campo e vários estudos foram conduzidos para análise e compreensão destes problemas visando à construção de uma prática profissional comprometida com o desenvolvimento integral das crianças.

Buscamos, dessa forma, compreender as relações sociais vividas dentro da dinâmica desigual de vida, as quais se confrontam com a implantação do ECA na realidade brasileira. Consideramos relevante destacar indicadores sociais da desigualdade social para que, então, pudéssemos nortear nosso entendimento, no que se refere às dificuldades de implementação e efetivação das políticas públicas, em especial a destinada à proteção de crianças pequenas e pobres.

\section{Os fundamentos}

A vida em uma sociedade capitalista, segundo Martín-Baró (2004), é marcada pela competência intergrupal e interindividual com intensa valorização pela propriedade privada. A resposta a este modo de vida revela um modelo competitivo de sociabilidade que se constitui elemento promotor e mantenedor da desigualdade social. Nas relações sociais dentro de uma escola de educação infantil, este modelo de sociabilidade também transparece pelas comparações e cobranças feitas, sobretudo àquelas crianças mais vulneráveis, sem uma compreensão mais ampliada das suas condições de vida.

Apesar de ser constantemente ressaltada a importância da democracia e dos direitos a uma vida digna para todos, Rizzini e Silva (2003) afirmam que as desigualdades econômicas, políticas e sociais aumentaram nos últimos anos, intensificando, consequentemente, a distância entre as pessoas que dispõem de recursos e poder e aquelas que permanecem à margem da sociedade. $\mathrm{Na}$ escola pública, a diferença entre educadores, crianças e suas famílias constitui-se como uma dimensão pouco estudada, mas fundamental para os processos de opressão e violação de direitos neste espaço de vida das crianças.

De acordo com dados obtidos por meio de uma pesquisa nacional - PNAD (Pesquisa Nacional por Amostra de Domicílios) realizada em 2009, pelo IBGE (Instituto Brasileiro de Geografia e Estatística) ${ }^{1}$, quase um quarto das famílias brasileiras $(24,7 \%)$ contavam com, pelo menos, um dos componentes com idade de até 14 anos e, para componentes com idade de até quatro anos, a proporção era de 7,2\% (Brasil, 2009). A partir desses dados, é possível afirmar que o Brasil precisa produzir indicadores sociais específicos para essa faixa etária, objetivando subsidiar o monitoramento das políticas públicas destinadas a essa população.

Outro dado relevante apontado por essa pesquisa nacional foi o rendimento familiar per capita e a frequência escolar. Verificou-se que $96,5 \%$ das crianças de 6 a 14 anos, as quais viviam em famílias cujo rendimento mensal domiciliar per capita era inferior a $1 / 4$ do salário mínimo, frequentavam a escola. Já as residências com rendimento mensal domiciliar per capita de um salário mínimo ou mais apresentaram um índice de $99 \%$ das crianças de 6 a 14 anos frequentando a escola (Brasil, 2009).

Conforme dados do PNAD, houve uma leve redução da taxa de analfabetismo, com aumento da taxa de escolarização. O tempo médio de escolarização de crianças de 10 anos ou mais foi de 7,2 anos. A taxa de escolarização de crianças de 6 a 14 anos foi de $97,6 \%$ e de jovens de 15 anos a 17 anos a proporção dos que frequentavam a escola foi de $85,2 \%$. Houve um aumento da frequência de crianças na escola, principalmente nas creches, e a rede pública foi a que continuou a receber o maior número de estudantes de ensino fundamental e médio.

$\mathrm{O}$ trabalho infantil concentrado na faixa etária entre 5 e 17 anos apresentou índice de $9,8 \%$ da população, sendo que a maior concentração $(48,1 \%)$ está entre os jovens de 14 a 17 anos (Brasil, 2009).

Outro órgão público federal, o Instituto de Pesquisa Econômica Aplicada (IPEA) ${ }^{2}$, vinculado ao Núcleo de Assuntos Estratégicos da Presidência da República, divulgou dados,

\footnotetext{
${ }^{1}$ Dados disponíveis no site: www.ibge.gov.br.

${ }^{2}$ Dados disponíveis no site: www.ipea.gov.br.
} 
em novembro de 2011, afirmando que desigualdade de renda domiciliar per capita média dos municípios caiu $22,8 \%$ nos últimos 30 anos. Esse Instituto informou que a diferença entre a renda dos moradores das cidades mais ricas e das mais pobres vem diminuindo, em especial pelo aumento da geração de empregos em regiões como o Nordeste. No entanto, é certo que as desigualdades regionais ainda são gritantes, já que os estados mais pobres têm um quarto da renda dos mais ricos. O índice de Gini dos municípios, o qual mede o grau de desigualdade existente na distribuição de indivíduos segundo a renda domiciliar per capita, em 1980 era de 0,31 e em 2010 caiu para 0,24 o que é um bom indicador, já que, quanto mais afastado de um, menor a desigualdade (Brasil, 2011).

De maneira mais estrita, nos dados de uma pesquisa acadêmica realizada por Euzébios Filho e Guzzo (2007), as condições de empregabilidade, a trajetória de vida, as condições de moradia e o acesso aos serviços de saúde e educação são apontados, pelos participantes, como fatores que evidenciam a desigualdade social. Os autores apontam que os participantes justificaram essa desigualdade pela condição econômica e social, sendo esta a forma básica de resumirem a qualidade de suas vidas e as relações sociais do capitalismo.

Especificamente, ao se referir à população infanto-juvenil, Zamora (2004) aponta que vários problemas associados à pobreza e à desigualdade social afetam essas pessoas, não só no Brasil, mas também na América Latina. Dentre esses problemas, a autora expõe a persistência das altas taxas de mortalidade infantil por causas que poderiam ser prevenidas; a qualidade da educação das crianças em função dos diferentes níveis socioeconômicos, do gênero, da etnia, da origem geográfica; o trabalho infantil, o urbano ou o rural, além dos altos índices de violência a que estão expostas cotidianamente.

O ECA é um instrumento jurídico, que busca assegurar a proteção e cuidados a todas crianças e adolescentes, tornando-os, pelo menos no plano das leis, cidadãos de direitos. Ele declara que os sujeitos, a quem se destina, devem ser tratados igualmente perante a lei e deve ser priorizada a sua proteção integral, sob três valores específicos: dignidade, liberdade e respeito (Brasil, 1990). No entanto, o que queremos ressaltar é que um instrumento jurídico com objetivo de universalizar direitos tem pouca efetividade em uma sociedade desigual, onde valores não são universalizados.

Tonet (2005) aponta que, na reflexão tradicional, os valores oscilam entre $\mathrm{o}$ subjetivismo e o objetivismo, mas com a predominância de uma concepção idealista dos valores, de que são uma criação subjetiva, ainda que demarcados socialmente. Já na posição marxiano-lukacsiana, os valores são elementos sociais, não tendo uma existência objetiva, são os homens que determinam o que é bom ou mau, certo ou errado, justo ou injusto, em função de sua condição objetiva de vida. $\mathrm{O}$ fundamento objetivo está presente nessa concepção dos valores na medida em que é o homem o responsável por estabelecer as qualidades do próprio objeto, determinando sua utilidade ou não, os fins que desejam atingir. Em suma, "os valores são produzidos pelos homens, de modo social, em momentos e locais diferentes da história do ser social.... todos têm como referência o processo de autoconstrução humana" (Tonet, 2005, p. 100).

O que é valorizado é o que priorizado. Valor é importância, é prioridade, sobretudo diante das condições objetivas e concretas de vida. Quando se prioriza a criança e seu desenvolvimento, seja ela rica ou pobre, as políticas públicas devem convergir para que as condições necessárias a este desenvolvimento possam, de fato, ocorrer. Liberdade, respeito e dignidade são valores expressos nos fundamentos que justificam o ECA. A questão aqui é buscar entender como educadores e pais compreendem estes valores, em especial o da dignidade, e como avaliam sua presença no cotidiano da vida, em casa e na escola.

De forma mais particular, em se tratando dos valores da trilogia do ECA, Ponce (2002) expõe que a liberdade se constrói a partir da humanidade e da sua História e evolui no sentido das relações estabelecidas entre a humanidade e o mundo e das relações mútuas dos seres humanos entre si, "quanto mais essas relações se humanizarem, mais a humanidade será livre ... humanização e libertação são, portanto, o mesmo" (Ponce, 2002, p.18). As relações estabelecidas entre o homem e o mundo e entre os próprios seres humanos deveria avançar, de forma articulada, na direção da liberdade, do respeito, da dignidade para todos em igualdade de condições. Entretanto, uma análise objetiva da realidade mostra 
evidências de que não podemos considerar que estes valores são priorizados na sociedade contemporânea.

O respeito e a dignidade estão diretamente relacionados quando se pensa em elaborar um conceito de liberdade. A partir desses três valores, o sujeito começa a reconhecer o valor de si, e reciprocamente admitir o valor do outro (Mello, 1999).

Para melhor compreendermos esse estudo, a dignidade da pessoa humana é o principal direito fundamental da Constituição de 1988 e voltou a ter destaque no Estatuto da Criança e do Adolescente. De acordo com Nunes (2002), a dignidade humana é parte da condição humana. Trata-se de um direito preenchido $a$ priori, isto é, só pelo fato de ser humano, a dignidade é fundante em sua condição de vida e desenvolvimento. $\mathrm{O}$ direito à vida $\mathrm{e}$ à dignidade são questões que se mantêm ao longo do desenvolvimento das pessoas na medida em que se desenvolvem e convivem socialmente.

No entanto, a efetivação de direitos em uma sociedade marcada pela desigualdade social passa a disputar posições prioritárias em um Estado que prioriza as relações econômicas em detrimento das relações sociais.

Há muito a ser feito para que o ECA possa efetivamente significar um instrumento de garantias dos direitos das crianças, passando pela necessidade do Estado valorizar a vida de crianças e adolescentes e das famílias de baixa renda (Marcílio, 2006; Mello, 1999).

$\mathrm{O}$ Estatuto proclama a igualdade de todas as crianças quanto ao direito à educação. Contudo, a condição concreta de espaços educativos para todas as crianças ainda não se efetivou. Fica evidente a errônea pretensão de que basta a lei para que a sociedade mude, no entanto, quando a lei aponta para direitos universais é dever de todos uma prática concreta que atenda ao que é formulado na lei (Souza Neto, 2003; Saeta \& Souza Neto, 2006).

De acordo com Saeta e Souza Neto (2006), a promulgação de leis iguais para todos, numa sociedade desigual, não é capaz e suficiente para transformar a sociedade. É preciso mais do que leis. É preciso que a sociedade se organize em busca de políticas sociais que respondam às suas necessidades e não às das políticas econômicas vigentes. Nisso reside o grande desafio de cunhar uma cultura política que supere o formalismo de querer solucionar as necessidades humanas e sociais apenas pelo aspecto jurídico. A solução para os problemas de ordem social está também em mudanças no modelo econômico, cultural e ético, sendo que, para as políticas sociais serem efetivadas precisam estar articuladas com as políticas econômicas.

Portanto, o ECA, por si só, não é capaz de garantir a vida digna, com liberdade e respeito às crianças, mas é preciso, fundamentalmente, que as relações sejam humanizadas, com condições sociais mais igualitárias. Não mudaram as condições de vida da grande maioria das crianças com a promulgação do ECA. Elas não saíram da pobreza, não deixaram de sofrer violência, não deixaram de sofrer os efeitos da desigualdade social. $\mathrm{O}$ fato de reconhecer os direitos, por si só, não foi capaz de garantir esta emancipação.

Assim sendo, tivemos por objetivo nesse estudo entender a compreensão que pais e educadores apresentaram quando se discutiu o valor da dignidade preconizada como direito no ECA.

\section{Método}

O trabalho aqui apresentado é um recorte de um amplo estudo realizado com educadores e pais de crianças que frequentavam uma escola municipal de educação infantil de uma cidade do interior do estado de São Paulo.

Entendemos como educadores todas as pessoas que estavam envolvidas de alguma forma com as crianças na escola, sendo elas professoras, educadoras especiais, orientadora pedagógica, diretora, vice-diretores, monitores, atendentes, funcionários da limpeza, da segurança ou da cozinha, já que todos deveriam assumir um papel de educador dentro da instituição.

No estudo, como um todo, procuramos ouvir pais e educadores a respeito da compreensão que tinham sobre os valores da liberdade, do respeito e da dignidade que embasam o ECA. Neste texto, focaremos a compreensão da dignidade. Como nossa inserção na escola acontecia uma vez por semana, ao longo de três anos, podemos caracterizar esse estudo como uma pesquisa de intervenção com um cunho qualitativo.

Os participantes foram 125 pais e 38 educadores. No grupo dos pais, $87 \%$ eram do sexo feminino, com idade entre 21 e 30 anos, sem emprego fixo e a maioria tinha até dois filhos. Os educadores eram $92 \%$ do sexo 
feminino, com idade entre 30 e 50 anos, com emprego fixo, tendo até dois filhos.

Semanalmente, participávamos de uma reunião coletiva de professores. Assim, apresentamos nossa proposta de estudo convidando-as a participarem da pesquisa. Após terem aceito, realizamos três encontros com as professoras, um em cada semana. Já para os pais, enviamos bilhetes convidando-os para virem à escola. Aos que atenderam o convite, apresentamos nosso estudo e os convidamos a participarem da pesquisa. Foi realizado um encontro de pais com cada uma das quinze turmas.

Foram realizados três encontros com os educadores, com duração aproximada de 45 minutos. Os educadores foram organizados em dois grupos para atender, tanto os que trabalhavam no turno da manhã, quanto no da tarde e passavam pelo mesmo momento de discussão, com a mesma temática, uma vez por semana. Como a escola contava com 15 turmas, divididas entre a CEMEI e a EMEI, realizamos um único encontro de pais em cada turma, com duração que variava de 30 minutos a uma hora e trinta minutos. As discussões dos grupos de pais aconteciam por sala de aula, e inicialmente eles discutiam livremente o conceito do valor e a seguir como ele era garantido ou violado em casa, na escola e na comunidade. A coleta desse material de pesquisa levou aproximadamente dois meses.

Serviram de fontes de dados um questionário, protocolos sobre o conceito da dignidade e protocolos da garantia e violação da dignidade em casa, na escola e na comunidade. O questionário, elaborado para caracterizar os participantes, continha dados como moradia, trabalho e número de filhos, o qual foi respondido anonimamente. Os protocolos se originaram a partir das transcrições dos encontros, os quais haviam sido gravados em fitas de áudio. Um desses protocolos continha as informações referentes à compreensão conceitual dos participantes sobre o conceito da dignidade e o outro protocolo era sobre a garantia e a violação da dignidade nos três espaços de convivência da criança.

As respostas obtidas nos encontros com pais e educadores, após as transcrições, passaram a compor os protocolos. A elaboração desses protocolos foi feita em duas etapas. Em um primeiro momento, fizemos a leitura de todas as transcrições dos encontros, tentando identificar que categorias estavam sendo abordadas. Após isso, partimos, de maneira mais específica, para uma nova leitura, tendo como base nossos objetivos. Foi a partir dessa segunda leitura que pudemos elaborar os protocolos.

Optamos em dividir os protocolos por grupos (de pais e de educadores) e por temas. Inicialmente construímos protocolos que contemplassem o conceito da dignidade oferecido pelo grupo de pais. A seguir, elaboramos protocolos que abordassem a garantia e a violação de cada valor a partir das discussões realizadas nos grupos de pais. Para o grupo de educadores seguimos a mesma dinâmica, fazendo protocolo do conceito da dignidade e da garantia e da violação da dignidade.

A pesquisa foi aprovada pelo Comitê de Ética em Pesquisa para ser desenvolvida no âmbito da escola por meio de grupos de discussão.

\section{Resultados e discussão}

As informações obtidas nos grupos de discussão foram gravadas, transcritas e analisadas em função da compreensão dos participantes sobre o valor da dignidade e sobre como esse direito pode ser garantido ou violado em casa, na escola e na comunidade. As informações foram analisadas separadamente tanto no grupo de pais quanto de educadores, para depois serem apresentadas em elementos de síntese. Exemplificaremos com trechos transcritos dos encontros cada elemento de síntese para a seguir tecer uma discussão sobre o que foi evidenciado.

\section{O que é dignidade para pais e educadores}

O grupo dos pais sistematizou o conceito de Dignidade considerando três unidades de sentido: direito à educação formal (possibilidade de acesso às instituições de ensino); atendimento das necessidades básicas (necessidades de moradia, alimentação, vestuário e saúde); relação com outros valores (associada a valores como respeito, liberdade, honestidade).

O estudo. Ele é um complemento na vida da pessoa, uma estrutura, acho que é uma parte, é uma maneira de o filho conseguir alguma coisa se os pais possibilitam isso, um futuro. 
Acho que é ter uma moradia decente, alimentação, saúde, atendimento médico.

é você mostrar o respeito a sociedade, as pessoas, é você passear com seus filhos $e$ você realmente poder dar aquela liberdade impondo limites e ela vai crescendo uma criança equilibrada

Os pais apontaram o acesso à educação formal como uma forma de vida digna, mas é necessário ficar evidente que as desigualdades sociais vividas privam a criança de usufruir dessa educação ou de tê-la com qualidade. Também evidenciaram o suprimento das necessidades de alimentação, moradia, vestuário e atendimento médico, sendo que a maneira como os pais dispõem para darem o necessário a seus filhos é por meio do trabalho. Contudo, mostraram-se conformados com o mínimo oferecido, achando que era o justo, não questionando ou reclamando, pois não se achavam merecedores de mais. Assim, se alienam diante do modelo capitalista de consumo. Enfatizaram, ainda, a presença de outros valores de cunho moral (honestidade, liberdade, respeito), sinalizando, possivelmente, a forma como a sociedade poderia estar embasada.

No protocolo da reunião de educadores da escola, foram destacadas as seguintes unidades de sentido para sistematizar o conceito de dignidade: atendimento das necessidades básicas (suprimento de alimentação, moradia e educação) e relação com a idade (aquilo que cada um pode fazer de acordo com a idade, dentro de certa faixa etária).

para a criança ter a dignidade, ela precisa ter as necessidades básicas, a educação, alimentação, moradia, falando assim das necessidades básicas para você levar uma vida digna, fora a questão de você ter uma família, de você ter carinho, de você ter uma pessoa que te dê uma base, um exemplo, uma estrutura para você se desenvolver.

dignidade é sempre você ser uma autoridade e autoridade no sentido de você ser autor da sua idade. (...) Ter dignidade é você poder ser uma autoridade, ser autor da sua idade. (...) é muito fácil você ver uma criança tendo atitude de adulto, ou cuidando da vida dele, ou se preocupando, ou sendo exigido que ele tenha comportamentos que não são adequados, então ele está perdendo a autoridade dele $e$ a dignidade também.

Os educadores, assim como os pais, acreditam que, para a criança viver dignamente, precisa ter supridas suas necessidades de alimentação e moradia. Esse grupo acrescentou como necessidade básica a educação. Não houve menção quanto à qualidade no atendimento dessas necessidades, mas em função das condições diferenciadas de vida dos educadores e dos pais e seus filhos, certamente os modelos que satisfaçam os dois grupos são distintos, marcados pelo acesso que cada um tem à alimentação, à moradia e à educação. No que se refere à faixa etária, a criança não deve ser responsável por situações incompatíveis com a sua idade ou ter atitudes características de adulto. As atribuições que algumas crianças têm com as tarefas domésticas podem ser distintas em cada família e estarem muito associadas ao trabalho dos pais e à falta de condições financeiras de manterem um funcionário para realizar esses afazeres.

Finalizando a discussão do conceito de dignidade, ficou evidente para os dois grupos que as necessidades básicas podem ser conseguidas por meio da compra. Alimentação, vestuário e moradia são produtos do trabalho humano, têm um valor de mercado estipulado e a qualidade e a quantidade desses produtos dependerá do poder de compra de cada família. Dessa forma, a compreensão dos participantes é de que a dignidade só pode ser concedida a uma criança a partir do suprimento de suas necessidades básicas. Principalmente o grupo de pais salientou que a educação formal é importante para a dignidade, não a educação oferecida pelas escolas públicas, mas aquela que as instituições privadas oferecem em troca de um valor pago.

Assim, nesse valor fica muito presente o domínio que o capital exerce sobre as pessoas. A dignidade assume assim um valor de mercado e não um valor moral e é essa concepção que será passada para as crianças e os adolescentes, estimulando a busca pelo ter mais, a competição e a desumanização das relações.

Nesse contexto, por mais explorados que os trabalhadores sejam, eles estão interessados, efetivamente, em aumentar seus salários, para então aumentarem o seu poder de compra. A dignidade será assim adquirida, já que as necessidades básicas referidas pelos 
participantes, além de serem supridas, poderão ser providas atendendo as grandezas qualidade e quantidade.

A desigualdade social pode ser aqui caracterizada, já que existem diferenças de acesso a determinados recursos. $\mathrm{O}$ alcance aos serviços privados, a moradia, a situação econômica das pessoas caracterizam a desigualdade social, de acordo com os participantes de um estudo realizado por Euzébios Filho e Guzzo (2007). Os pesquisadores evidenciaram que os participantes não conseguiram refletir de uma forma mais abrangente, associaram, diretamente, o dinheiro como consequência da desigualdade social, sem compreenderem que ele é consequência da realidade vivida, marcada pela desigualdade de renda.

\section{A garantia e a violação da dignidade nas relações com pais e educadores}

Apresentaremos os resultados dos dois grupos de participantes, sobre a garantia e a violação da dignidade em casa, na escola e na comunidade. Utilizamos também unidades de sentido com o objetivo de melhor explicitar as ideias advindas dos grupos de discussão realizados.

Os dados advindos dos pais não nos informaram nenhuma unidade de sentido de garantia da dignidade na escola e na comunidade, apenas duas unidades de sentido da garantia em casa: condições financeiras dos pais (aquilo que podem oferecer aos filhos desde que tenham trabalho e salário adequado) e pais como exemplos (os pais servem de modelo para os filhos, em muitas circunstâncias do cotidiano).

O mínimo de dignidade que uma criança possa ter é o pai ter um salário para poder sustentar a criança.

... se você for seguindo os exemplos dos pais, eles são certinhos, aquela árvore vai crescendo direitinho, raramente segue pelo caminho errado.

Fica evidente a preocupação dos pais, quanto à dignidade, com o poder aquisitivo advindo do trabalho. Acreditam que, a partir do momento em que tiverem um trabalho que lhes remunere satisfatoriamente, poderão oferecer uma vida mais digna a seus filhos. Também é dada ênfase no exemplo que os pais devem ser para seus filhos, pois é nesse modelo que o filho irá se espelhar e agir.

Quanto à violação da dignidade em casa, as unidades de sentido foram: dificuldades financeiras dos pais (limitações materiais dos pais) e pais não servindo de modelos para os filhos (pais precisam ser capazes de passar bons exemplos aos filhos).

eu acho que uma boa alimentação ajuda. Por exemplo: a senhora ganha mil reais, $e$ eu ganho 350, a senhora vai comer melhor do que eu, vai usar roupa melhor do que a minha.

Então se a criança vê os pais fazendo errado, vai aprendendo o errado, nós somos os exemplos.

Presenciamos aqui a importância que é dada, pela sociedade, à renda de cada família e àquilo que poderá ser desfrutado a partir dela, mas não é feita nenhuma crítica quanto à distribuição da renda em nosso país. Evidenciamos ainda que a criança será, segundo os pais, o reflexo do meio em que estiver inserida, em especial no ambiente familiar. Ao oferecer exemplos considerados inapropriados, os pais estarão violando a dignidade de seus filhos.

A partir dos dados dos pais, no espaço da escola, foram evidenciadas as seguintes unidades de sentido que se referiam à violação da dignidade: qualidade do ensino (educação formal sendo capaz de cumprir seus objetivos); diferenças e desigualdade no ensino (o ensino público e o privado diferem quanto aos conteúdos ensinados, o que pode ocasionar possibilidades diferenciadas no acesso ao conhecimento); não suprimento das necessidades (a escola não deve atender apenas as demandas das crianças, mas também dos pais) e falta de prioridade para a educação (parcos recursos destinados ao ensino público).

Hoje em dia os filhos da gente vão da $1^{a}$ a $6^{a}$ série e você manda ler uma receita e não conseguem ler.

Aí o governo coloca lá a manchete: 66 mil vagas em escola particular para o PROUNI. Mas a maioria das pessoas que vão lá nunca estudaram em escola pública, só em escola particular.

ela ter escola, na medida em que necessita. Mas também na medida em que você necessita, porque você coloca a criança às 
8 horas na escola e tem que tirar as 12, como que você faz se não tá em casa, se tá no trabalho?

E eu li no C. (jornal) domingo que os políticos nunca vão investir em escolas públicas porque eles querem cada vez mais pessoas analfabetas no Brasil.

Os pais consideraram que a dignidade de seus filhos estará sendo violada se o ensino oferecido não for capaz de alfabetizar as crianças na etapa adequada, se os professores não estiverem comprometidos com aquilo que fizerem e se o governo não investir na qualidade da educação oferecida.

Outro ponto de destaque é o que evidencia a falta de opções dos pais em colocarem seus filhos em escolas em período integral ou de terem alguém que possa ficar com eles enquanto trabalham, criando um problema social bastante grave, mesmo sendo evidente que as vagas são destinadas às crianças e não aos pais.

Cabe destacar ainda a falta de opções dos pais, que precisam submeter seus filhos a frequentarem escolas em condições precárias. No entanto, são poucos os que fazem reclamações oficiais quanto a isso, muitas vezes por receio de perder a vaga de seu filho.

As unidades de sentido serviços disponíveis (precariedade e dificuldades enfrentadas pela população quando precisam dos serviços públicos) e desinteresse do Estado (os três níveis governamentais não evidenciam seu papel) foram evidenciadas pelos pais como violação da dignidade no espaço da comunidade.

Há mais ou menos seis ou sete anos moro aqui e acho horrível. Você tem que ir de madrugada para poder pegar ficha, aí você consegue agendar pra dali um mês, então você vai para o pronto-socorro ou para outro lugar. E aí com criança pequena como que você vai tão cedo para a fila? É complicado. $O$ posto funciona das 8 as $16 e$ aí fica difícil.

Só ouvi do estatuto quando tem que punir alguém e cadê a garantia dos direitos?

Os pais fazem críticas quanto aos interesses do Estado, os quais violam as necessidades da população, em especial, das crianças. Apontam, no entanto, os deveres a que estão submetidos, mas sem recompensas, já que não há garantia de que seus direitos serão efetivados. Os pais acabam se submetendo ao descaso do Estado em vários setores e, consequentemente, sofrem os resultados disso tudo na qualidade de vida que levam e que podem oferecer a seus filhos.

Já para as discussões que aconteceram nos grupos de educadores pudemos elaborar, para a garantia da dignidade em casa, a unidade de sentido presença dos pais (participação efetiva e ativa dos pais na educação dos filhos); para a garantia do direito na escola, a unidade de sentido relações familiares com reflexo na escola (interferência das relações familiares na escola), e para expressar a garantia da dignidade na comunidade, a unidade de sentido relação entre adultos e crianças (adultos servindo de modelos para as crianças e o não envolvimento de crianças em assuntos inapropriados).

Em contrapartida a criança que mora lá na favela, não tô generalizando, às vezes não tem essa dignidade da parte financeira, mas tem muito mais a qualidade da presença da mãe e do pai, a conversa, a orientação, a explicação, o exemplo mesmo de vida do que uma criança que mora lá no condomínio, que muitas vezes não tem nem mesmo a conversa, não consegue conversar com o pai.

... lá na Cemei a gente presta bem atenção nessa questão em relação os pais com as crianças, em relação ao ambiente, então o cuidar dessa criança é os pais trazerem a criança com uma roupa limpa, ter dentro da mochilinha uma roupa limpa para trocar, isso eu acho que é dignidade, porque nem todas as crianças têm esse direito garantido.

... o adulto gosta de viver em dignidade, gosta de ter respeito e consegue se impor e como é que a criança vai fazer isso? Ela precisa ter garantido por um adulto, quem é que dá essa garantia? É o adulto. A gente que tem que modificar o nosso padrão de relacionamento, de comportamento, de atenção, de dedicação com a criança para dar uma vida mais saudável, digna.

Para os educadores, a dignidade é garantida em casa quando os pais, moradores da favela, estão mais em contato com seus filhos do que os pais que moram nos condomínios, levando a crer que isso acontece 
porque os moradores das favelas convivem mais proximamente com o desemprego ou com trabalhos informais. Acreditamos que essa não seja uma relação linear, que automaticamente expressa a qualidade do relacionamento simplesmente pela presença do adulto junto de seu filho. É necessário um estreitamento das relações para que isso de fato aconteça.

O contexto de vida e as condições financeiras a que os pais estão submetidos não são levadas em consideração e muitos educadores deixam-se levar por concepções preconceituosas e avaliações da aparência para tecerem comentários depreciativos com relação aos pais e às crianças.

Alguns educadores deixavam claro que não queriam saber o que acontecia na casa da criança, quais eram suas condições de vida, físicas e emocionais, apenas relatavam que estavam na escola para dar as quatro horas de aula e o restante não interessava. Ao alienaremse de toda situação, muitas vezes, não conseguiam compreender por que uma criança agia de determinada maneira. Entendemos que tomar conhecimento das condições de vida da criança com a qual o educador tem um vínculo diário pode causar-lhe sofrimento, podendo essa ser uma forma de proteger-se, mas, em contrapartida, pode auxiliar na compreensão do desenvolvimento infantil e na tomada de atitudes.

Pelos diálogos travados nos grupos de educadores, ficou evidente que existem atribuições e soluções que competem ao mundo adulto e outras, as crianças, não devendo haver interferências que venham prejudicar $o$ desenvolvimento infantil. $\mathrm{O}$ adulto se torna responsável por garantir a dignidade da criança ao protegê-la, não permitindo que se envolva em situações inadequadas.

Já para a violação da dignidade em casa, a unidade de sentido surgida foi denominada condições financeiras (oferecimento de diferentes recursos materiais); na escola, as unidades de sentido representativas foram definidas como políticas educacionais (forma autoritária como as políticas educacionais entram na escola) e valores diferentes (crítica a respeito da diferença na forma de valorização de pais e crianças para educação, sentimentos e bens de consumo); e a unidade de sentido submissão ao ter (maior valorização ao ter do que ao ser) foi elaborada para expressar a violação da dignidade na comunidade. mas hoje não, a criança exige dos pais que ela quer isso, quer aquilo, é um ciclo vicioso. A criança pede, o pai dá porque não pode dar atenção e tudo vai girando, tem mais e quer mais.

Acho que a dignidade da escola está se perdendo. A partir do momento que o discurso de cima, da cúpula da prefeitura vem que é um adulto por criança, eles não dizem, é um educador por criança, é um adulto para 18 crianças, não é um educador para 18 crianças, não importa quem seja, pode ser o guarda, pode ser o professor que é obrigado a ter curso universitário ou pode ser o monitor. Igualaram o monitor com o professor então todos têm que limpar bumbum, todos têm que trabalhar, não existe mais... Então eu acho que a escola perdeu a dignidade, e isso tá tirando a dignidade do professor e a dignidade da criança.

As pessoas valorizam o que não devia ser tão valorizado, por exemplo, os pais não tem dinheiro para contribuir com 5,00 reais por mês com a APM (Associação de Pais e Mestres) da escola, mas aí as crianças aparecem com tudo o que é novidade de sandalinha, bolsinha, batonzinho, roupinha, mochila, então os valores são outros e não na educação.

eu posso falar que na minha família tem os três níveis e os que mais têm, não tem essa preocupação, não tem esse tipo de pensamento, conserva o móvel antigo, conserva os valores trazidos e os que tão subindo, melhorando, o que eles querem ter? A tela de plasma, o melhor computador, então é uma coisa muito grave, porque você nesse patamar essa classe, imagine os de baixo que já estão comprando a tela de plasma em 60 vezes. Ele não tem parede suficiente para colocar, porque tijolo furado não aguenta.

Nessas unidades de sentido, fica evidente a importância que é dada à aquisição de bens materiais, e isso estaria violando a dignidade infantil ao não priorizar e não valorizar aspectos da convivência, do relacionamento interpessoal na sociedade. De acordo com os educadores, a dignidade é violada em casa quando os pais tentam suprir certas lacunas nos seus relacionamentos com os filhos, oferecendo 
presentes e objetos que julgam ser de interesse das crianças.

A partir das informações, pode-se perceber que, no cotidiano escolar, há uma exacerbação do discurso, o qual é carregado de cobranças e reclamações. No entanto, poucas são as ações práticas dos profissionais da escola que levam a alguma mudança efetiva. As alterações são desejadas no discurso, em contrapartida, encontram baixa aceitação na realidade, gerando um quadro de acomodação.

Assim, a valorização do ser humano, nessa sociedade, por meio da aquisição de objetos de consumo, faz com que as pessoas que vivem a exclusão social, no dia a dia, sintam-se de alguma forma mais inseridas no sistema dominante. Esses pais podem não acreditar que a educação será a forma de diminuir a desigualdade social $\mathrm{e}$ os educadores os criticam, pois certamente não sofrem, na mesma intensidade, a exclusão vivida por essa parcela da população.

A dignidade, de acordo com os resultados, pode ser garantida quando os adultos possuem determinadas condições financeiras para suprirem as necessidades das crianças e ainda quando os pais podem conviver cotidianamente, de maneira mais próxima, com seus filhos. No modelo de sociedade em que vivemos, isso acaba sendo muito contraditório, já que a busca por atingir esses recursos faz com que muitos pais precisem se afastar de casa, por muitas horas, ficando alheios à vida dos filhos.

As cobranças pessoais e o modelo de sociedade vigente faz com que muitos pais busquem exaustivamente aquisições materiais no intuito de oferecer um outro padrão de vida para seus filhos. É a eterna luta para se sentir reconhecido socialmente, já que:

A civilização capitalista ocidental, em sua forma atual, cria valores que permeiam as relações sociais, a cultura e a educação como um todo. O Capital e o Mercado constituem-se na estrutura fundante deste regime. Nesse regime, quem tem mais vale mais, quem não tem nada, não vale nada. (Guzzo, 2007, p. 18)

Conciliar esses dois fatores, aquisição material e presença dos pais, torna-se uma tarefa penosa e difícil de atingir, não por desinteresse dos pais, mas pelas próprias cobranças impostas. Dentro desse modelo, os cuidados com as crianças, ou a intenção de que eles aconteçam, acabam sendo direcionados de diferentes formas. Algumas crianças ficam sozinhas, ou sob os pretensos cuidados dos próprios irmãos, às vezes ainda crianças também; outras são cuidadas por familiares; há ainda a contratação de vizinhos ou pessoas disponíveis; e também, quando é possível contar com os recursos disponíveis na comunidade, como creches ou escolas que atendam em período integral.

A desigualdade social não se reduz pela formulação de políticas sociais e sim por um enfrentamento direto ao sistema capitalista. Embora, inicialmente, essas políticas possam propiciar melhorias para a vida de segmentos da população, elas não asseguram direitos a todos. As políticas sociais das últimas décadas elaboradas para garantir o controle social buscam encobrir os fracassos das políticas sociais de desenvolvimento, por meio dos programas sociais (Souza Neto, 2003).

Os programas sociais assumem um caráter assistencialista que serve apenas como uma forma remediativa da situação de pobreza e miséria vivida pela grande parte da população. No entanto, é preciso mobilizar e conscientizar a população para alterar esse quadro de desigualdades, rompendo com a alienação dominante, pois conforme Saeta e Souza Neto (2006, p. 39):

Se a barbárie da sociedade brasileira é pautada na desigualdade social, na violência e na negação dos direitos, o processo civilizatório é marcado por diferentes formas de lutas para conquistar e garantir esses direitos.

\section{Conclusões}

As informações obtidas a partir dessa pesquisa nos permitiram refletir sobre o valor da dignidade presente na trilogia do Estatuto da Criança e do Adolescente, tendo como base alguns fatos do cotidiano de uma escola pública de educação infantil expressos pelos pais e educadores da instituição.

Para os participantes, a garantia da dignidade sempre esteve associada com a aquisição material, com as condições financeiras de cada família. A dignidade só seria alcançada pelas crianças se os pais tivessem recursos financeiros para lhes oferecerem alimentação, moradia, vestuário, estudo em escolas privadas. Do contrário, esse 
direito estaria sendo violado. No entanto, o Estatuto (1990) não menciona explicitamente que a dignidade deva ser garantida pelas condições econômicas, mas que ela é violada pelo tratamento desumano, vexatório, constrangedor, violento ou aterrorizante.

Fica muito evidente o domínio que os recursos financeiros exercem sobre as pessoas como se, sem isso, não fosse possível ter a garantia da dignidade. A dignidade assume assim um valor de mercado e não um valor moral e é essa concepção que será passada para crianças e adolescentes, estimulando a busca pelo ter mais, a competição e a desumanização Nesse contexto, por mais explorados que os trabalhadores sejam, eles estão interessados, efetivamente, em aumentar seus salários, para então aumentarem o seu poder de compra. A dignidade será assim adquirida, já que as necessidades básicas referidas pelos participantes, além de serem supridas, poderão ser providas atendendo a qualidade $\mathrm{e}$ quantidade.

Percebemos, ao longo desse estudo, que a violação da dignidade de uma criança é marcada não só pela desigualdade social, mas também pela sua geradora, que é a desigualdade de renda.

Nessa busca por melhores condições financeiras, alguns pais fizeram com que seus filhos ficassem expostos a situações de vulnerabilidade. Os pais, oprimidos, buscavam conquistar bens de consumo que os aproximassem de classes sociais com um poder aquisitivo maior. Para eles, a maior aproximação acontece em virtude daquilo que se ostenta, uma vez que na sociedade capitalista o ser humano é valorizado pelo o que tem e não pelo o que é.

O papel do psicólogo escolar diante desse quadro poderá ser o de fortalecer as relações entre família e escola, na tentativa de haver uma maior aproximação para que se possam abrir espaços de discussão sobre o tema, a fim de, se não erradicá-lo, ao menos, diminuí-lo. O trabalho intersetorial também assume um grau de importância, à medida que o psicólogo estiver inserido nas redes de apoio social à criança, para auxiliar na tomada de decisões, dando suporte ao educador, à família e à criança.

O profissional de Psicologia, ao estar inserido na instituição e podendo participar de outros espaços de discussão que atinjam a escola, poderia fazer a articulação entre os equipamentos públicos, auxiliando na problematização da realidade e na reflexão do contexto social, rompendo com a frequente culpabilização da criança e de sua família (Weber \& Guzzo, 2008).

De acordo com Sant'Ana, Costa e Guzzo (2008), o psicólogo escolar poderá auxiliar na desmistificação de rótulos e preconceitos, além de contribuir para que se identifique as contradições existentes entre as políticas de proteção à criança e a efetivação das ações dos diferentes segmentos que compõem a rede de proteção a essa população.

Assim, no transcorrer dessa pesquisa ficou evidente que a formulação de uma lei visa atender algumas exigências da vida em sociedade, no entanto a sua efetivação vai muito além do simples fato de existir, até porque uma lei não trata, na realidade, diferentes como iguais. Muitos fatores que influenciam diretamente o cotidiano das pessoas precisam ser levados em consideração, ao procurarmos entender valores e necessidades em uma sociedade com as características da vida que vivemos.

\section{Referências}

Brasil (1990). Estatuto da Criança e do Adolescente. Recuperado em 10 de março, 2005, de http://www.planalto.gov.br. Recuperado em 10 de março de 2005.

Brasil (2009). Pesquisa Nacional por Amostra de Domicílios. Recuperado em 07 de março, 2012, de http://www.ibge.gov.br.

Brasil (2011). Instituto de Pesquisa Econômica Aplicada. Recuperado em 12 de março, 2012, de http://www.ipea.gov.br.

Euzébios Filho, A., \& Guzzo, R. S. L. (2007). A desigualdade social vista por seus atores. In I. O. Dobles, S. B. Arróliga, \& V. L. Zuñiga (Eds.), Psicologia de la liberación em el contexto de la globalización neoliberal (pp. 336-352.). San José: UCR.

Guzzo, R. S. L. (2005). Escola Amordaçada: Compromisso do psicólogo escolar. In A. Mitjáns Martinez (Org.), Psicologia escolar e compromisso social (pp. 17-29). Campinas: Alínea. 
Guzzo, R. S. L. (2007). Desenvolvimento da criança: um processo histórico e participativo. In R. S. L. Guzzo (Org.), Desenvolvimento infantil: família, proteção e risco (pp. 07-11). Campinas: Alínea.

Instituto Brasileiro de Geografia e Estatística (2009). Recuperado em 12 de março, 2012, de http://www.ibge.gov.br.

Marcílio, M. L. (2006). A lenta construção dos direitos da criança brasileira - século XX. Recuperado em 19 de setembro, 2006, de http://www.cefetsp.br/edu/eso/cidadania/ml uizausp.html..

Martín-Baró, I. (2004). Acción e ideologia: Psicologia social desde centroamérica $\left(10^{\mathrm{a}}\right.$ Ed.). El Salvador: UCA editoras.

Martínez, A. M. (2007). O psicólogo escolar e os processos de implantação de políticas públicas: atuação e formação. In H. R. Campos (Org.), Formação em psicologia escolar: realidade e perspectivas (pp. 109134). Campinas: Alínea.

Mello, S. L. (1999). Estatuto da criança e do adolescente: é possível torná-lo uma realidade psicológica? Psicologia USP, 10(2). Recuperado em 06 de setembro, 2006, de http://www.scielo.br.

Nunes, R. (2002). O princípio constitucional da dignidade da pessoa humana: Doutrina $e$ Jurisprudência. São Paulo: Saraiva.

Ponce, B. J. (2002). A aventura da liberdade. In A. Martini et al. (Orgs.), O humano, lugar do sagrado (pp. 15-21). São Paulo: Olho d'Água.

Rizzini, I., \& Silva, N. C. R. d. (2003). Direitos humanos e direitos da criança e do adolescente: Reflexões sobre desigualdades sociais e a questão dos "meninos de rua". In S. M. G. Sousa (Org.), Infância e adolescência: Múltiplos olhares (pp. 99111). Goiânia: Editora da UCG.

Saeta, B. R. P., \& Souza Neto, J. C. d (2006). A criança $\mathrm{e} O \mathrm{O}$ adolescente na sociedade brasileira. In J. C. d Souza Neto, \& M. L. B. P. Nascimento (Orgs.), Infância: instituições e políticas públicas (pp. 17-41). São Paulo: Expressão e Arte.
Sant'Ana, I. M., Costa, A. S., \& Guzzo, R. S. L. (2008). Escola e vida: compreendendo uma realidade de conflitos e contradições. Pesquisa e práticas psicossocias, 2(2), 302311.

Souza, M. P. R. (2007). Reflexões a respeito da atuação do psicólogo no campo da psicologia escolar/educacional em uma perspectiva crítica. In H. R. Campos (Org.), Formação em psicologia escolar: realidade e perspectivas (pp. 149-162). Campinas: Alínea.

Souza Neto, J. C. d (2003). A trajetória do menor a cidadão. São Paulo: Editora Expressão e Arte.

Tonet, I. (2005). Educação, cidadania $e$ emancipação humana. Ijuí: Editora Unijuí.

Vectore, C., \& Maimoni, E. H. (2007). A formação do psicólogo escolar e a atuação em instituições infantis. In H. R. Campos (Org.), Formação em Psicologia Escolar: realidades e perspectivas (pp. 135-147). Campinas: Alínea.

Weber, M. A. L., \& Guzzo, R.S.L. (2008). Redes de proteção à criança vítima de violência doméstica: o compromisso dos órgãos públicos. Manuscrito em preparação. Campinas: PUC-Campinas.

Zamora, M. H. (2004). Otra América Latina para los niños y adolescentes. In I. Rizzini, M. H. Zamora, \& R. F. Corona (Eds.), Niños $y$ adolescentes creciendo en contextos de pobreza, marginalidad y violencia en América Latina (pp. 19-34). Rio de Janeiro: CIESPI.

Recebido em 02 de Julho de 2010

Texto reformulado em 03 de Maio de 2012 Aceite em 23 de Maio de 2012 Publicado em 31 de Dezembro de 2012 